\title{
A functional heparan sulfate mimetic implicates both heparanase and heparan sulfate in tumor angiogenesis and invasion in a mouse model of multistage cancer
}

Johanna A Joyce, Craig Freeman, Nicole Meyer-Morse, Christopher R Parish and Douglas Hanahan

Oncogene (2005) 24, 4163. doi:10.1038/sj.onc.1208770

Correction to: Published online 4 April 2005

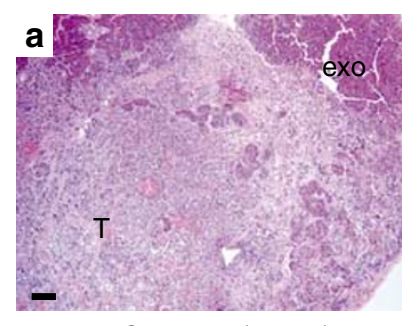

PBS control (13.5w)

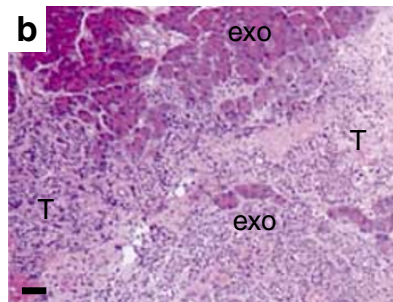

e

$\square$ tumor (Tum)

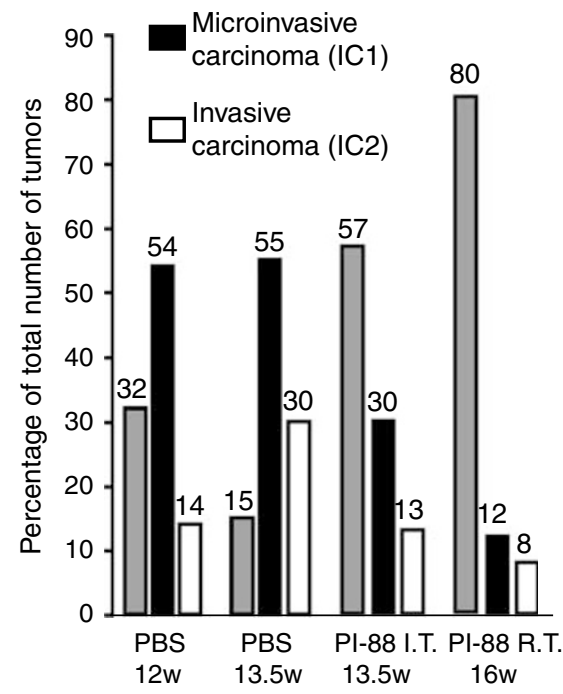

Since publication of the above manuscript, the authors have identified an error in Figure 7. The correct figure is shown here.
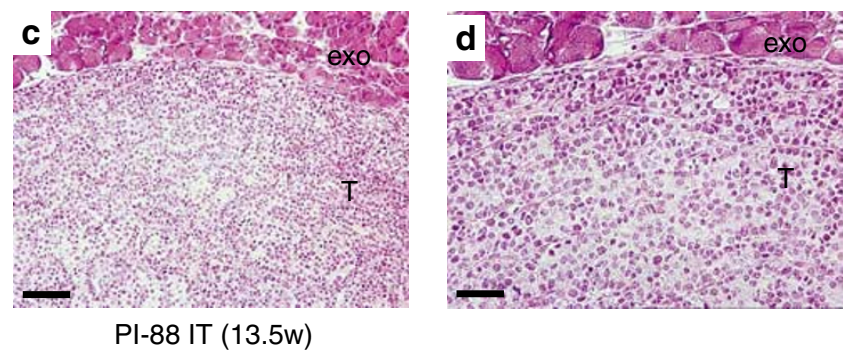

f

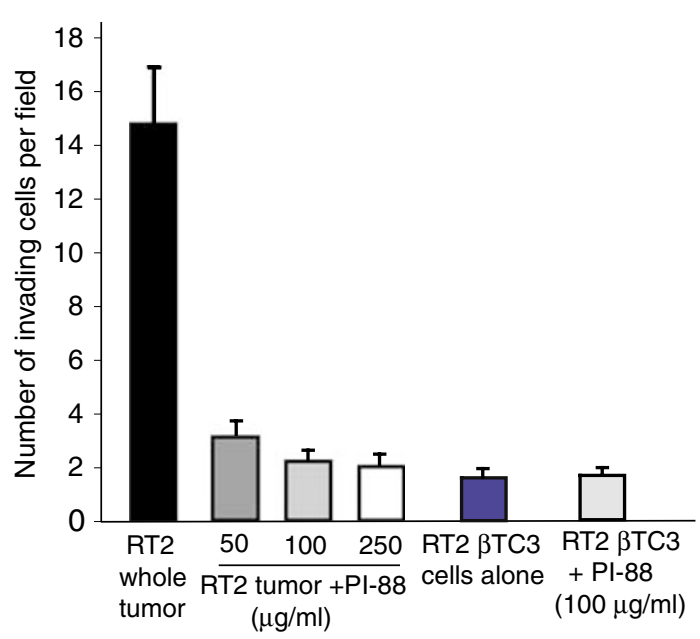

